\title{
Feasibility and efficacy of chemoradiotherapy with concurrent split-dose cisplatin after induction chemotherapy with docetaxel/cisplatin/5-fluorouracil for locally advanced head and neck cancer
}

\author{
TOMOYA YOKOTA ${ }^{1 *}$, MASAYUKI SHIBATA ${ }^{1 *}$, SATOSHI HAMAUCHI ${ }^{1}$, HIROMICHI SHIRASU ${ }^{2}$, \\ YUSUKE ONOZAWA ${ }^{2}$, HIROFUMI OGAWA ${ }^{3}$, TSUYOSHI ONOE ${ }^{3}$, TAKESHI KAWAKAMI ${ }^{1}$, \\ MITSUHIRO FURUTA ${ }^{1}$, HIROTO INOUE ${ }^{1}$, KUNIHIRO FUSHIKI ${ }^{1}$ and TETSURO ONITSUKA ${ }^{4}$ \\ ${ }^{1}$ Division of Gastrointestinal Oncology; ${ }^{2}$ Division of Medical Oncology; ${ }^{3}$ Division of Radiation Oncology; \\ ${ }^{4}$ Division of Head and Neck Surgery, Shizuoka Cancer Center, Shizuoka 411-8777, Japan
}

Received March 27, 2020; Accepted June 12, 2020

DOI: $10.3892 / \mathrm{mco} .2020 .2105$

\begin{abstract}
Chemoradiotherapy (CRT) with concurrent high-dose cisplatin (CDDP) is a standard treatment for locally advanced squamous cell carcinoma of the head and neck (LA-SCCHN). Docetaxel plus CDDP and 5-fluorouracil (TPF) induction chemotherapy (ICT) prior to CRT is considered for patients at high risk of distant metastases. The purpose of the current study was to evaluate the feasibility and efficacy of CRT with split-dose CDDP after TPF-ICT for LA-SCCHN. A total of 21 LA-SCCHN patients treated with TPF-ICT followed by concurrent CRT with split-dose CDDP between January 2011 and December 2017 were retrospectively analysed. The patients' characteristics were i) median age 66 years (48-75 years); ii) male/female, 21/0; iii) performance status $0-1 / 2,20 / 1$; iv) larynx/hypopharynx/oropharynx/oral cavity, $4 / 8 / 8 / 1$ and v) clinical stage III/IV, 3/18. The numbers of TPF-ICT cycles $1 / 2 / 3$ were $2 / 3 / 16$. Median cumulative doses of CDDP in TPF-ICT and CRT were 180.0 and $206.7 \mathrm{mg} / \mathrm{m}^{2}$, respectively. All patients completed 70 Gy RT. The complete response rate was $76.2 \%$. At a median follow-up of 51.5 months, median PFS and OS were not reached and 65.5 months, respectively. The most common grade 3 or worse toxicities during CRT-ICT were stomatitis (48\%), dysphagia (21\%), anorexia (17\%) and
\end{abstract}

Correspondence to: Dr Tomoya Yokota, Division of Gastrointestinal Oncology, Shizuoka Cancer Center, 1007 Shimonagakubo, Nagaizumi, Sunto-gun, Shizuoka 411-8777, Japan

E-mail: t.yokota@scchr.jp

*Contributed equally

Key words: locally advanced squamous cell carcinoma of the head and neck, chemoradiotherapy, induction chemotherapy, split-dose concurrent high-dose cisplatin, nephrotoxicity, neurotoxicity, ototoxicity leukopenia (14\%). However, no grade 2 or worse nephrotoxicity, neurotoxicity or ototoxicity was observed. The results demonstrated that concurrent CRT with split-dose CDDP after TPF-ICT is feasible and effective for LA-SCCHN.

\section{Introduction}

Chemoradiotherapy (CRT) with concurrent high-dose $\left(100 \mathrm{mg} / \mathrm{m}^{2}\right.$ every 3 weeks) cisplatin (CDDP) is a standard treatment for patients with locally advanced squamous cell carcinoma of the head and neck (LA-SCCHN) (1-4). However, high-dose CDDP is often unfeasible for patients with advanced age, and renal, cardiac, or neurogenic dysfunction. Therefore, clinical studies regarding CRT with high-dose CDDP have targeted limited patients with normal organ function and good general condition $(1,2)$.

Because no statistically significant improvement in survival has been shown in several phase 3 trials comparing induction chemotherapy (ICT) followed by CRT versus CRT alone (5-8), the benefit of ICT for all patients with LA-SCCHN is controversial. However, ICT prior to CRT is still an option for cases classified as clinical nodal stage N2c, N3, which have a high risk of distant metastasis in our clinical practice. According to randomized phase 3 trials comparing ICT regimens, the standard regimen of ICT is docetaxel plus CDDP and fluorouracil (TPF) (9-11). Notably, high-dose CDDP-based CRT after TPF-ICT is often associated with nephrotoxicity, neurotoxicity, and ototoxicity, partly because of the cumulative CDDP dosage $(12,13)$. Thus, it has been an unmet need that subsequent CRT regimens after TPF-ICT should be optimized. The purpose of this study was to evaluate the efficacy and safety of TPF-ICT followed by concurrent CRT with split-dose CDDP as an alternative regimen of high-dose CDDP in our clinical practice.

\section{Patients and methods}

Patients. This study involved patients with LA-SCCHN stage III or IV (Union for International Cancer Control Tumor, Node, 
Metastasis classification, 7th Edition) who were treated with TPF-ICT followed by split-dose CDDP plus RT at Shizuoka Cancer Center between January 2011 and December 2017. Patients were selected based on the following criteria: (1) Age $\geq 20$ years; (2) Eastern Cooperative Oncology Group (ECOG) Organization performance status (PS) $\leq 2$; and (3) histologically confirmed diagnosis of squamous cell carcinoma of head and neck. For oropharyngeal cancer, HPV positivity was examined, which was defined as positive for p16 on immunohistochemistry. Approval for this study was obtained from the Institutional Review Board of Shizuoka Cancer Center and met the standards set forth in the Declaration of Helsinki. Written informed consent was obtained from all patients in this study.

Treatment. The TPF-ICT regimen consisted of DOC $\left(70 \mathrm{mg} / \mathrm{m}^{2}\right)$ and CDDP $\left(70 \mathrm{mg} / \mathrm{m}^{2}\right)$ given IV on day 1 and a continuous infusion of $5-\mathrm{FU}\left(750 \mathrm{mg} / \mathrm{m}^{2} /\right.$ day) for 5 days. TPF was repeated every 3 weeks for three cycles. Patients were administered prophylactic antibiotics, ciprofloxacin or levofloxacin, at every cycle to prevent bacterial infections. Granulocyte colony-stimulating factor was used in patients with grade 4 or febrile neutropenia. Subsequently, patients received concurrent CRT. Selection of a concurrent CRT regimen with split-dose CDDP regimen was at the physician's discretion. The administration of radiation therapy was performed at a total dose of 70 Gy given in single, daily, 2-Gy fractions. Single-agent CDDP at $20 \mathrm{mg} / \mathrm{m}^{2}$ was administered intravenously on days 1-4, 22-25, and 43-46. Three-dimensional conformal RT or intensity-modulated RT was applied.

Evaluation. All clinical data were retrospectively obtained from electronic medical records. We evaluated pre-treatment information, including demographic features, physical examination results, laboratory tests, computed tomography (CT), magnetic resonance imaging (MRI), and ${ }^{18} \mathrm{~F}$-fluorodeoxyglucose positron-emission tomography/CT fusion imaging (PET-CT) findings. Tumor response was assessed by CT or MRI at 6-8 weeks after completing RT or when clinical signs suggested progressive disease. Adverse events were evaluated according to the Common Terminology Criteria for Adverse Events (CTCAE) v4.0.

Statistical analysis. The overall survival (OS) was measured from the first day of CRT until the day of death from any cause or censored at the last follow-up visit. Progression-free survival (PFS) was calculated from the first day of CRT until disease relapse by imaging, or censored at the last confirmation of survival. The survival curves were generated using the Kaplan-Meier method. We used the Mann-Whitney U test for comparisons of continuous variables and Fisher's exact test for comparisons of categorical variables between the groups. P-values $<0.05$ were considered statistically significant. All statistical analyses were performed using EZR (Saitama Medical Center, Jichi Medical University, Saitama, Japan), a graphical user interface for R version 2.13.0 (The R Foundation for Statistical Computing, Vienna, Austria).

\section{Results}

Patient characteristics. During the study period, 38 LA-SCCHN patients had undergone concurrent CRT with split-dose CDDP. Of these, 17 patients were excluded, including 3 patients with nasopharyngeal carcinoma, 6 patients who had undergone surgery before the administration of CRT, and 8 patients who had not undergone ICT. In total, 21 patients were included in this study. The patients' characteristics before starting TPF-ICT are shown in Table I. Median age was 66 years (48-75 years). All patients were male. Eighteen patients $(86 \%)$ were at clinical stage IV. All patients had an ECOG performance status (PS) of 0 to 1 . Of eight patients with oropharyngeal cancer, 2 patients had evidence of p16-positive squamous-cell carcinoma on tissue specimen.

Treatment compliance. The treatment compliance of TPF-ICT and CRT with split-dose CDDP is shown in Table II. Sixteen patients $(76 \%)$ completed three cycles of TPF-ICT. The median cumulative dose of CDDP in TPF-ICT was $180.0 \mathrm{mg} / \mathrm{m}^{2}$ (57.1-206.0 mg/m²). All patients completed 70 Gy RT. RT pause was required in 3 patients $(14.3 \%)$. The rate of completion of CDDP, which is designated as cases with no dose reduction of CDDP and no delay in CDDP administration, was $61.9 \%$. Three cycles of CDDP administration were performed in 14 patients $(66.7 \%)$. The median cumulative dose of CDDP in concurrent CRT with split-dose CDDP was $206.7 \mathrm{mg} / \mathrm{m}^{2}$ $\left(65.1-233.0 \mathrm{mg} / \mathrm{m}^{2}\right)$. Thirteen patients $(61.9 \%)$ received a cumulative dose of CDDP of more than $200 \mathrm{mg} / \mathrm{m}^{2}$ during CRT. The median duration of CRT was 50 days.

Treatment outcome. The objective response rate (ORR) after TPF-ICT was documented in 17 patients $(81.0 \%)$, including no cases with complete response (CR) and $17(81.0 \%)$ with partial response (PR). After the completion of CRT, CR was documented in 16 patients $(76.2 \%)$ and PR in 3 patients $(14.3 \%)$. The median length of follow-up for censored cases was 51.5 months (range, 30.7-94.4). Median PFS was not reached and 5-year PFS was $52.4 \%$ (Fig. 1). Median OS was 65.5 months. 3-year and 5-year OS was 60.4 and 52.9\%, respectively (Fig. 2).

Adverse events associated with CRT. The grade of toxicities observed during CRT is demonstrated in Table III. The most common grade 3 or worse toxicities were stomatitis $(48 \%)$, dysphagia (21\%), anorexia (17\%), and leukopenia (14\%). However, there was no grade 2 or worse nephrotoxicity, neurotoxicity, or ototoxicity. We further compared creatinine clearance (Cockcroft and Gault equation), ototoxicity, and neurotoxicity before CRT (after TPF-ICT) with those after CRT. There was no deterioration of renal, auditory and neural function even after CRT (Table IV). No treatment-related deaths were observed.

\section{Discussion}

The present study retrospectively investigated the efficacy and feasibility of TPF-ICT followed by concurrent CRT with split-dose CDDP. Complete response was achieved in $76.2 \%$ after CRT, and long-term follow-up of survival confirmed that the median OS was 65.5 months. Acute toxicities as well as late ones were manageable and acceptable. These findings suggest that split-dose CDDP is an effective regimen for patients with LA-SCCHN after TPF-ICT using high-dose CDDP. 
Table I. Patient characteristics $(n=21)$.

\begin{tabular}{|c|c|}
\hline Characteristics & Number of patients \\
\hline Median age, years (range) & $66(48-75)$ \\
\hline \multicolumn{2}{|l|}{ Sex } \\
\hline Male & 21 \\
\hline Female & 0 \\
\hline \multicolumn{2}{|l|}{ PS (ECOG) } \\
\hline 0 & 14 \\
\hline 1 & 7 \\
\hline \multicolumn{2}{|l|}{ Primary site } \\
\hline Larynx & 4 \\
\hline Hypopharynx & 8 \\
\hline Oropharynx & 8 \\
\hline Oral cavity & 1 \\
\hline \multicolumn{2}{|l|}{ T stage } \\
\hline $\mathrm{T} 1$ & 2 \\
\hline $\mathrm{T} 2$ & 10 \\
\hline T3 & 3 \\
\hline $\mathrm{T} 4$ & 6 \\
\hline \multicolumn{2}{|l|}{$\mathrm{N}$ stage } \\
\hline No & 2 \\
\hline N1 & 1 \\
\hline $\mathrm{N} 2$ & 18 \\
\hline N3 & 0 \\
\hline \multicolumn{2}{|l|}{ Disease stage } \\
\hline III & 3 \\
\hline IV & 18 \\
\hline \multicolumn{2}{|l|}{ Resectability } \\
\hline Resectable & 10 \\
\hline Unresectable & 11 \\
\hline \multicolumn{2}{|l|}{ Smoking history } \\
\hline$\geqq 10$ pack-years & 20 \\
\hline$<10$ pack-years & 1 \\
\hline \multicolumn{2}{|l|}{ Habitual alcohol use } \\
\hline Yes & 15 \\
\hline No & 6 \\
\hline \multicolumn{2}{|l|}{ Histological differentiation } \\
\hline Poorly & 5 \\
\hline Moderate & 10 \\
\hline Well & 1 \\
\hline Unknown & 5 \\
\hline \multicolumn{2}{|c|}{ HPV status (Oropharyngeal cancer) } \\
\hline Positive & 2 \\
\hline Negative & 6 \\
\hline
\end{tabular}

ECOG, Eastern Cooperative Oncology Group; PS, performance status; HPV, Human papillomavirus.

It is recommended that the total cumulative dose of CDDP used in combination with radiation be more than $200 \mathrm{mg} / \mathrm{m}^{2}$ because reducing the total CDDP dose influences the treatment
Table II. Treatment compliance.

\begin{tabular}{lc}
\hline A, TPF-ICT & \\
\hline Treatment & Number of patients $(\%)$ \\
\hline Number of cycles & \\
1 & $2(9.5)$ \\
2 & $3(14.3)$ \\
3 & $16(76.2)$ \\
Median cumulative dose of & $180.0(57.1-206.0)$ \\
CDDP (mg/m ${ }^{2}$ ) (range) & \\
\hline & \\
B, CRT & \\
\hline RT (70 Gy) completion rate & $21(100)$ \\
RT pause rate & $3(14.3)$ \\
CDDP completion rate & \\
Number of CDDP cycles & $13(61.9)$ \\
1 & \\
2 & $2(9.5)$ \\
3 & $5(23.8)$ \\
Median cumulative dose of & $14(66.7)$ \\
CDDP (mg/m ${ }^{2}$ (range) & \\
CRT duration (day) & \\
\hline
\end{tabular}

${ }^{a}$ CDDP completion rate was defined as that of the patients with no dose reduction and delay of CDDP. CDDP, cisplatin; TPF-ICT, docetaxel plus CDDP and fluorouracil induction chemotherapy; $\mathrm{RT}$, radiotherapy; CRT, chemoradiotherapy.

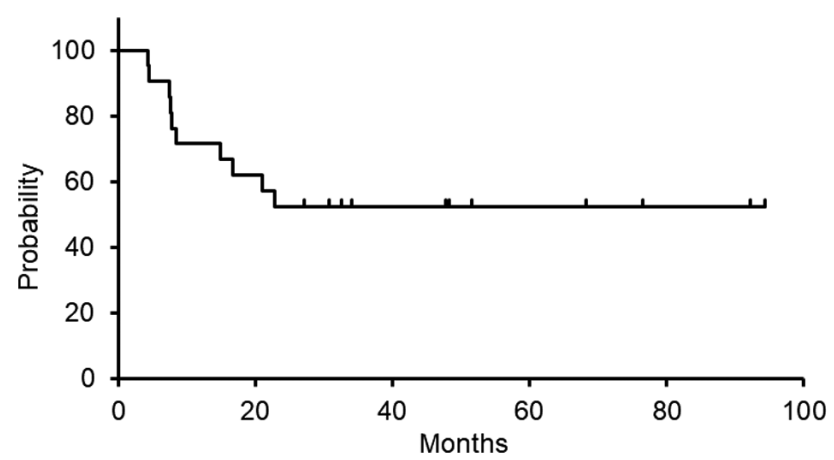

Figure 1. Kaplan-Meier plot showing progression-free survival $(\mathrm{n}=21)$ Progression-free survival was calculated from the first day of TPF induction chemotherapy until disease relapse by imaging, or censored at the last confirmation of survival.

outcome $(14,15)$. However, the National Comprehensive Cancer Network (NCCN) guidelines do not recommend high-dose CDDP (100 mg/m² every 21 days, three times) after CDDP-based ICT because of toxicity concerns (16). Indeed, one patient experienced decreased creatinine clearance $(46.9 \mathrm{ml} / \mathrm{min})$ and in another patient PS deteriorated (PS2) after TPF-ICT in our study. These findings suggest that, in some patients receiving TPF-ICT, high-dose CDDP in the following CRT phase is not feasible. Furthermore, 


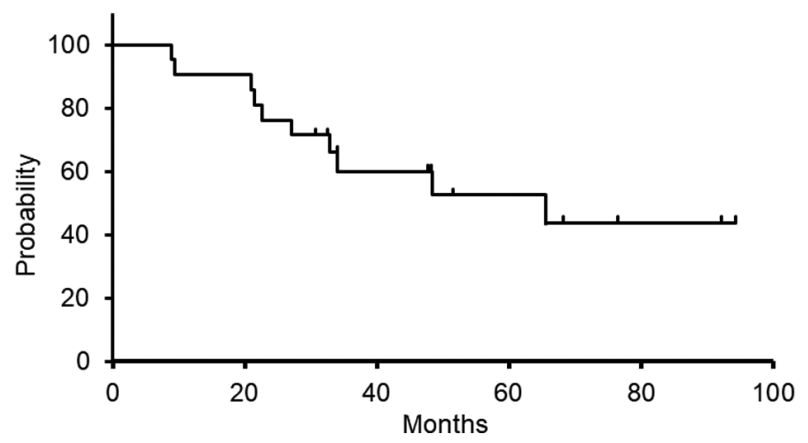

Figure 2. Kaplan-Meier plot showing overall survival $(\mathrm{n}=21)$. The overall survival was measured from the first day of TPF induction chemotherapy until the day of death from any cause or censored at the last follow-up visit.

the TREMPLIN randomized phase II study, in which ICT followed by CRT using high-dose CDDP was compared with ICT followed by cetuximab plus radiotherapy for larynx preservation, revealed that residual renal dysfunction (grade 1) and grade 3-4 neuropathy were observed in 22.4 and $3.4 \%$ of cases after CRT, respectively (17). Late toxicities induced by high-dose CDDP included nephrotoxicity, neurotoxicity, and ototoxicity (17-20), which are irreversible and likely to reduce quality of life in patients treated with CRT.

CDDP-induced nephrotoxicity is dose-dependent and involves necrosis, apoptosis, and necroptosis of renal cells (21-24). It is also well known that CDDP-induced neuropathy is dose-dependent, with symptoms typically occurring at cumulative doses of greater than $350 \mathrm{mg} / \mathrm{m}^{2}$ (25-29). Notably, the risk of neurotoxicity was also reported to increase with higher single doses of CDDP (26,28-31). Furthermore, it has been reported that symptoms continued to progress even after the cessation of treatment in more than half of patients treated with high-dose CDDP (29).

To reduce the high-dose CDDP-associated toxicities after TPF-ICT, alternative methods of CDDP administration without reducing the total dosage should be optimized. Split-dose CDDP has been conventionally used for head and neck cancers as an alternative to high-dose CDDP. A prospective study of TPF-ICT followed by concurrent CRT with split-dose CDDP regimen was performed (32). This trial targeted unresectable LA-SCCHN alone, whereas ours targeted both resectable and unresectable cases. The treatment compliance and efficacy of TPF and subsequent CRT in our study are consistent with those in this previous study. However, no data are available regarding late toxicities. We also followed up late toxicities, focusing on nephrotoxicity, neurotoxicity, and ototoxicity. Our safety profile revealed no grade 2 or worse nephrotoxicity, neurotoxicity, or ototoxicity, whereas overall grade 3 or worse toxicities occurred in $76.2 \%$ of cases. These results suggest that the method of split-dose administration without reducing the total dosage could decrease CDDP-related toxicities without compromising treatment outcomes.

Instead of high-dose CDDP, alternative CRT regimens after TPF have been suggested. A randomized phase 3 trial comparing TPF-ICT followed by CRT or by cetuximab-RT in patients with unresectable LA-SCCHN is ongoing (33). Although the definitive results are yet to be released, this trial
Table III. Adverse events associated with CRT.

\begin{tabular}{lrr}
\hline Adversity & Any Gr, n $(\%)$ & $\geqq \mathrm{Gr} 3, \mathrm{n}(\%)$ \\
\hline Stomatitis & $21(100)$ & $14(48)$ \\
Dysphagia & $20(95)$ & $6(21)$ \\
Anorexia & $21(100)$ & $5(17)$ \\
Leukopenia & $17(81)$ & $4(14)$ \\
Infection & $2(7)$ & $2(7)$ \\
Febrile neutropenia & $2(7)$ & $2(7)$ \\
Anemia & $20(95)$ & $1(3)$ \\
Thrombocytopenia & $18(86)$ & $1(3)$ \\
Nausea & $15(71)$ & $1(3)$ \\
Radiation dermatitis & $21(100)$ & $1(3)$ \\
Dry mouth $^{\text {Ototoxicity }}{ }^{\mathrm{a}}$ & $21(100)$ & $1(3)$ \\
Neuropathy $^{\mathrm{a}}$ & $3(10)$ & $0(0)$ \\
AST/ALT elevation $_{\text {Creatinine elevation }}{ }^{\mathrm{a}}$ & $1(3)$ & $0(0)$ \\
\hline
\end{tabular}

${ }^{\mathrm{a}}$ Grade 2 or worse nephrotoxicity, neurotoxicity, or ototoxicity was not observed. CRT, chemoradiotherapy; Gr, grade.

Table IV. Comparison of renal function, ototoxicity, and neurotoxicity before and after CRT.

\begin{tabular}{lccc}
\hline Renal function factor & Pre CRT & Post CRT & P-value \\
\hline $\begin{array}{l}\text { Median creatinine } \\
\text { clearance (ml/min) } \\
\text { (range) }\end{array}$ & $\begin{array}{l}85.6 \\
(46.9-115.1)\end{array}$ & $\begin{array}{c}85.1 \\
(49.6-98.7)\end{array}$ & 0.94 \\
$\begin{array}{l}\text { Ototoxicity } \\
\text { Neuropathy }^{\mathrm{a}}\end{array}$ & 1 & 3 & 0.606 \\
& 1 & 1 & 1.000
\end{tabular}

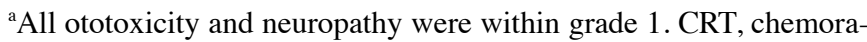
diotherapy.

aims to evaluate the non-inferiority of cetuximab-RT versus CRT in terms of overall survival. Furthermore, the combination of carboplatin with RT was conventionally utilized after ICT in several large clinical trials, such as the TAX324 (9) and PARADIGM trials (8). Against this background, carboplatin or cetuximab used concurrently with radiation could be options after TPF.

Our study has a number of limitations. First, this study is statistically underpowered due to its small sample size. The retrospective study design at a single center may have led to selection bias. There were also no definitive criteria for the concurrent CRT regimen with split-dose CDDP. The selection of concurrent CRT regimen was at the physician's discretion.

In conclusion, the sequential strategy of TPF-ICT followed by concurrent CRT with split-dose CDDP may be tolerable and efficacious in the treatment of LA-SCCHN. However, the most appropriate CRT regimens after TPF-ICT, in terms of late toxicities and survival outcome, need to be investigated in a future randomized study. 


\section{Acknowledgements}

Not applicable.

\section{Funding}

No funding was received.

\section{Availability of data and materials}

The data that support the findings of this study are available from Shizuoka Cancer Center but restrictions apply to the availability of these data, which were used under license for the current study, and so are not publicly available. Data are however available from the authors upon reasonable request and with permission of Shizuoka Cancer Center.

\section{Authors' contributions}

TY, MS, SH, HS, YO, HO, TOno, TK, MF, HI, KF, and TOni participated in the research design. Acquisition of the data was performed by MS and TY. Interpretation of the data was conducted by all authors. The manuscript was prepared and written by TY and MS. All authors read and approved the final manuscript.

\section{Ethics approval and consent to participate}

Approval for the current study was obtained from the Institutional Review Board of Shizuoka Cancer Center.

\section{Patient consent for publication}

Not applicable.

\section{Competing interests}

The authors declare that they have no competing interests.

\section{References}

1. Forastiere AA, Goepfert H, Maor M, Pajak TF, Weber R, Morrison W, Glisson B, Trotti A, Ridge JA, Chao C, et al: Concurrent chemotherapy and radiotherapy for organ preservation in advanced laryngeal cancer. N Engl J Med 349: 2091-2098, 2003.

2. Adelstein DJ, Li Y, Adams GL, Wagner H Jr, Kish JA, Ensley JF, Schuller DE and Forastiere AA: An intergroup phase III comparison of standard radiation therapy and two schedules of concurrent chemoradiotherapy in patients with unresectable squamous cell head and neck cancer. J Clin Oncol 21: 92-98, 2003.

3. Pignon JP, Bourhis J, Domenge C and Designé L: Chemotherapy added to locoregional treatment for head and neck squamous-cell carcinoma: Three meta-analyses of updated individual data. MACH-NC collaborative group. Meta-analysis of chemotherapy on head and neck cancer. Lancet 355: 949-955, 2000.

4. Pignon JP, le Maître A, Maillard E and Bourhis J; MACH-NC Collaborative Group: Meta-analysis of chemotherapy in head and neck cancer (MACH-NC): An update on 93 randomised trials and 17,346 patients. Radiother Oncol 92: 4-14, 2009.

5. Zhang L, Jiang N, Shi Y, Li S, Wang P and Zhao Y: Induction chemotherapy with concurrent chemoradiotherapy versus concurrent chemoradiotherapy for locally advanced squamous cell carcinoma of head and neck: A meta-analysis. Sci Rep 5: $10798,2015$.
6. Haddad RI, Posner M, Hitt R, Cohen EEW, Schulten J, Lefebvre JL and Vermorken JB: Induction chemotherapy in locally advanced squamous cell carcinoma of the head and neck: Role, controversy, and future directions. Ann Oncol 29: 1130-1140, 2018.

7. Budach W, Bölke E, Kammers K, Gerber PA, Orth K, Gripp S and Matuschek C: Induction chemotherapy followed by concurrent radio-chemotherapy versus concurrent radio-chemotherapy alone as treatment of locally advanced squamous cell carcinoma of the head and neck (HNSCC): A meta-analysis of randomized trials. Radiother Oncol 118: 238-243, 2016.

8. Haddad R, O'Neill A, Rabinowits G, Tishler R, Khuri F, Adkins D, Clark J, Sarlis N, Lorch J, Beitler JJ, et al: Induction chemotherapy followed by concurrent chemoradiotherapy (sequential chemoradiotherapy) versus concurrent chemoradiotherapy alone in locally advanced head and neck cancer (PARADIGM): A randomised phase 3 trial. Lancet Oncol 14: 257-264, 2013.

9. Vermorken JB, Remenar E, van Herpen C, Gorlia T, Mesia R, Degardin M, Stewart JS, Jelic S, Betka J, Preiss JH, et al: Cisplatin, fluorouracil, and docetaxel in unresectable head and neck cancer. N Engl J Med 357: 1695-1704, 2007.

10. Posner MR, Hershock DM, Blajman CR, Mickiewicz E, Winquist E, Gorbounova V, Tjulandin S, Shin DM, Cullen K, Ervin TJ, et al: Cisplatin and fluorouracil alone or with docetaxel in head and neck cancer. N Engl J Med 357: 1705-1715, 2007.

11. Blanchard P, Bourhis J, Lacas B, Posner MR, Vermorken JB, Cruz Hernandez JJ, Bourredjem A, Calais G, Paccagnella A, Hitt R, et al: Taxane-cisplatin-fluorouracil as induction chemotherapy in locally advanced head and neck cancers: An individual patient data meta-analysis of the meta-analysis of chemotherapy in head and neck cancer group. J Clin Oncol 31: 2854-2860, 2013.

12. Caballero M, Mackers P, Reig O, Buxo E, Navarrete P, Blanch JL and Grau JJ: The role of audiometry prior to high-dose cisplatin in patients with head and neck cancer. Oncology 93: 75-82, 2017.

13. Mizuno T, Ishikawa K, Sato W, Koike T, Kushida M, Miyagawa Y, Yamada K, Hirata S, Imai E and Noda Y: The risk factors of severe acute kidney injury induced by cisplatin. Oncology 85: 364-369, 2013

14. Nguyen-Tan PF, Zhang Q, Ang KK, Weber RS, Rosenthal DI, Soulieres D, Kim H, Silverman C, Raben A, Galloway TJ, et al: Randomized phase III trial to test accelerated versus standard fractionation in combination with concurrent cisplatin for head and neck carcinomas in the radiation therapy oncology group 0129 trial: Long-term report of efficacy and toxicity. J Clin Oncol 32: 3858-3866, 2014.

15. Loong HH, Ma BB, Leung SF, Mo F, Hui EP, Kam MK, Chan SL, $\mathrm{Yu}$ BK and Chan AT: Prognostic significance of the total dose of cisplatin administered during concurrent chemoradiotherapy in patients with locoregionally advanced nasopharyngeal carcinoma. Radiother Oncol 104: 300-304, 2012.

16. NCCN guidelines with NCCN evidence blocks ${ }^{\mathrm{TM}}$-head and neck cancers version 1,2020

17. Lefebvre JL, Pointreau Y, Rolland F, Alfonsi M, Baudoux A, Sire C, de Raucourt D, Malard O, Degardin M, Tuchais C, et al: Induction chemotherapy followed by either chemoradiotherapy or bioradiotherapy for larynx preservation: The TREMPLIN randomized phase II study. J Clin Oncol 31: 853-859, 2013.

18. Hitt R, Grau JJ, López-Pousa A, Berrocal A, García-Girón C, Irigoyen A, Sastre J, Martínez-Trufero J, Brandariz Castelo JA, Verger E, et al: A randomized phase III trial comparing induction chemotherapy followed by chemoradiotherapy versus chemoradiotherapy alone as treatment of unresectable head and neck cancer. Ann Oncol 25: 216-225, 2014.

19. Adelstein DJ, Moon J, Hanna E, Giri PG, Mills GM, Wolf GT and Urba SG: Docetaxel, cisplatin, and fluorouracil induction chemotherapy followed by accelerated fractionation/concomitant boost radiation and concurrent cisplatin in patients with advanced squamous cell head and neck cancer. A Southwest oncology group phase II trial (S0216). Head Neck 32: 221-228, 2010.

20. Driessen CML, Leijendeckers J, Snik A, van der Graaf WTA, de Boer JP, Gelderblom H, Kaanders JHAM, Takes R and van Herpen CML: Ototoxicity in locally advanced head and neck cancer patients treated with induction chemotherapy followed by intermediate or high-dose cisplatin-based chemoradiotherapy. Head Neck 41: 488-494, 2019.

21. Lieberthal W, Triaca V and Levine J: Mechanisms of death induced by cisplatin in proximal tubular epithelial cells: Apoptosis vs. necrosis. Am J Phys 270: F700-F708, 1996. 
22. Lee RH, Song JM, Park MY, Kang SK, Kim YK and Jung JS Cisplatin-induced apoptosis by translocation of endogenous Bax in mouse collecting duct cells. Biochem Pharmacol 62: 1013-1023, 2001.

23. Ozkok A and Edelstein CL: Pathophysiology of cisplatin-induced acute kidney injury. Biomed Res Int 2014: 967826, 2014.

24. Volarevic V, Djokovic B, Jankovic MG, Harrell CR, Fellabaum C, Djonov V and Arsenijevic N: Molecular mechanisms of cisplatin-induced nephrotoxicity: A balance on the knife edge between renoprotection and tumor toxicity. J Biomed Sci 26: 25 , 2019.

25. Park SB, Goldstein D, Krishnan AV, Lin CS, Friedlander ML, Cassidy J,KoltzenburgMandKiernanMC: Chemotherapy-induced peripheral neurotoxicity: a critical analysis. CA Cancer J Clin 63: 419-437, 2013.

26. Oldenburg J, Fosså S and Dahl A: Scale for chemotherapy-induced long-term neurotoxicity (SCIN): Psychometrics, validation, and findings in a large sample of testicular cancer survivors. Qual Life Res 15: 791-800, 2006.

27. LoMonaco M, Milone M, Batocchi AP, Padua L, Restuccia D and Tonali P: Cisplatin neuropathy: Clinical course and neurophysiological findings. J Neurol 239: 199-204, 1992.

28. van den Bent MJ, van Putten WL, Hilkens PH, de Wit R and van der Burg ME: Retreatment with dose-dense weekly cisplatin after previous cisplatin chemotherapy is not complicated by significant neuro-toxicity. Eur J Cancer 38: 387-391, 2002.

29. von Schlippe M, Fowler CJ and Harland SJ: Cisplatin neurotoxicity in the treatment of metastatic germ cell tumour: Time course and prognosis. Br J Cancer 85: 823-826, 2001.
30. Cavaletti G, Marzorati L, Bogliun G, Colombo N, Marzola M, Pittelli MR and Tredici G: Cisplatin-induced peripheral neurotoxicity is dependent on total-dose intensity and single-dose intensity. Cancer 69: 203-207, 1992.

31. Brydøy M, Oldenburg J, Klepp O, Bremnes RM, Wist EA, Wentzel-Larsen T, Hauge ER, Dahl $O$ and Fosså SD: Observational study of prevalence of long-term Raynaud-like phenomena and neurological side effects in testicular cancer survivors. J Natl Cancer Inst 101: 1682-1695, 2009.

32. Okano S, Enokida T, Onoe T, Ota Y, Motegi A, Zenda S, Akimoto T and Tahara M: Induction TPF chemotherapy followed by CRT with fractionated administration of cisplatin in patients with unresectable locally advanced head and neck cancer. Int J Clin Oncol 24: 789-797, 2019.

33. Hitt R, Mesia R, Grau JJ, Iglesias L, Del Barco E, Lozano A, Trufero JM, Giron CG, Martin AL and Hernandez JJC: Randomized phase III trial of induction chemotherapy (ICT) with docetaxel-cisplatin-5fluorouracil (DCF) followed by cisplatin-radiotherapy (CRT) or cetuximab-radiotherapy (CetRT) in patients (pts) with locally advanced unresectable head and neck cancer (LAUHNC). J Clin Oncol 34: (15 Suppl): S6001, 2016. 